\title{
A OCUPAÇÃO DO SUDOESTE E OESTE DO PARANÁ E A LUTA PELA TERRA: O CASO DA REVOLTA DOS POSSEIROS DE $1957^{* 1}$
}

\author{
Silvestre Kieskoski \\ André Paulo Castanha
}

\section{INTRODUÇÃO}

O presente texto resulta das atividades de pesquisa, ensino e extensão desenvolvidas junto ao Grupo de Pesquisa: História, Sociedade e Educação no Brasil - HISTEDOPR, GT Local do HISTEDBR Nacional e tem impactos diretos nos cursos de graduação e pós-graduação da Unioeste, instituição, a qual estamos vinculados. O HISTEDOPR é um grupo multicampi e tem produzido conhecimentos sobre educação, história e história da educação regional e nacional.

Este capítulo teve origem no material produzido com fins didáticos para atender um dos requisitos do Programa de Desenvolvimento Educacional do Paraná - PDE/PR, turma 2010. A partir daquele material ampliamos o texto com o objetivo de fazer um estudo bibliográfico e documental, procurando analisar o processo de ocupação da região Sudoeste e Oeste do Paraná, articulado ao movimento conhecido como "Marcha para o Oeste", e, procurando analisar mais especificamente o Levante dos Posseiros de 1957, na região Sudoeste do Paraná, buscando contribuir com os professores e alunos na articulação dos conteúdos de história local, regional e nacional.

Como indicaram Sbardelotto e Castanha, a ocupação do território do Sudoeste e Oeste do Paraná teve relação direta com a política do governo Vargas, conhecida como "Marcha para Oeste", sucedendo a ocupação argentina e paraguaia, cuja base foi a extração de erva-mate e madeira. Tal

\footnotetext{
*DOI - 10.29388/978-65-86678-77-2-0-f.91-106

${ }^{1}$ Uma primeira versão deste texto foi produzida e publicada como parte do Caderno Pedagógico elaborado durante a realização do Programa de Desenvolvimento Educacional - PDE/PR, recebendo o título de "Produção do Conhecimento: o desafio para o ensino de história" e está disponível no seguinte endereço: http://www.nre.seed.pr.gov.br/franciscobeltrao/arquivos/File/formacao_acao/geografia/caderno_tematico_silvestre_kieskoski.pdf. Está versão foi revisada e ampliada para compor está coletânea.
} 
política possibilitou o desenvolvimento regional, mas acabou gerando conflitos entre os colonos e as companhias colonizadoras, "ocasionando violentas disputas pela posse da terra entre posseiros e colonizadoras, expresso no levante armado conhecido como 'Revolta dos Posseiros de 1957', no Sudoeste do Estado" (2018, p. 191).

O capítulo está organizado em cinco tópicos: no primeiro tratamos sinteticamente do processo de povoamento e ocupação da região Sudoeste e Oeste do Paraná; no segundo analisamos a criação de Colônia Agrícola Nacional General Osório (CANGO) e do Território Federal do Iguaçu (TFI) e seus impactos na colonização; em seguida abordamos a atuação das empresas colonizadoras, especialmente da Clevelândia Industrial Territorial Ltda. (CITLA), principal agente do conflito com os posseiros no Sudoeste do Paraná; o quarto tópico é o objeto central deste texto, trata especificamente da Revolta dos Posseiros em 1957, no Sudoeste do Paraná; no quinto, ressaltamos os desdobramentos da luta pela regularização das propriedades e o papel do Grupo Executivo para as Terras do Sudoeste do Paraná (GETSOP). Por fim apresentamos breves conclusões sobre a história da colonização de nossa região.

Temos ciência das limitações do texto, mas, como também é nosso objetivo estimular alunos e professores a conhecer, estudar e pesquisar a história regional, contamos com o envolvimento de mais pessoas para se debruçar sobre o tema, alargando assim, o conhecimento sobre nossa história.

\section{POVOAMENTO DO SUDOESTE E OESTE DO PARANÁ}

Desde o início da colonização do Brasil, o território do atual Sudoeste e Oeste do Paraná passou por diversas fazes de ocupação. Os historiadores têm apresentado ao menos quatro. A primeira frente de ocupação foi a indígena com tribos da família Tupi-Guarani (Mbÿá, Nhandeva, Nhanteté e Avá-Guarani) e Jê (Kaingang e Xokleng - botocudos). A segunda se deu pela ação de espanhóis e portugueses a partir do final do século XV.

A terceira teve início após a independência do Brasil, com a penetração de argentinos e paraguaios, mediante ações independentes ou pelo sistema de obrages (WACHOWICZ, 2002). Foi nessa terceira fase que a região Sudoeste foi objeto de disputas pelo seu território, envolvendo, primeiramente Brasil e Argentina e depois Paraná e Santa Catarina.

A partir de meados do século XIX, uma vasta região territorial, na qual estava inserido o atual Sudoeste do Paraná, foi objeto de disputa entre o Brasil e a Argentina. Depois de diversas tentativas de acordo, o conflito foi resolvido pela mediação de Grover S. Cleveland, presidente dos Estados Unidos, o qual 
deu ganho de causa ao Brasil, em 05 de fevereiro de1895. Assim, a disputa por parte do território das Missões, situado na faixa da atual fronteira entre Brasil e Argentina - entre os Rios Iguaçu e Uruguai - definidos atualmente como Oeste Catarinense e Sudoeste do Paraná terminou. O episódio ficou conhecido até hoje como questão das Missões ou de Palmas. Em consideração ao papel desempenha pelo presidente americano na mediação do conflito, a população do município de Bela Vista de Palmas, optou por mudar o nome do município, passando a denomina-lo de Clevelândia a partir de 1909.

Segundo Wachowicz (2002), encerrada a questão entre Brasil e Argentina, recomeçou a disputa entre Paraná e Santa Catarina, que já disputavam o território desde a criação da Província do Paraná em 1853. Tanto Paraná, como Santa Catarina desejavam a posse dessa rica região fronteiriça que se estendia desde o rio Uruguai até o rio Iguaçu. $O$ conflito só foi resolvido com o fim da guerra do Contestado (1912-1916), quando um acordo foi assinado entre Paraná e Santa Catarina e confirmado pelo Presidente Wenceslau Braz, em 20 de outubro de 1916. A partir desta data a região do Sudoeste do Paraná, passou a pertencer definitivamente ao Estado do Paraná.

A quarta frente de ocupação das atuais regiões Sudoeste e Oeste do Paraná se deu com a chegada dos migrantes sulistas, provenientes, em sua maioria, do Rio Grande do Sul e Santa Catarina a partir da segunda metade da década de 1940 (PADIS, 1981).

De acordo com Lazier, o processo de ocupação da região Sudoeste passou por três momentos significativos: a) A criação da Colônia Agrícola Nacional General Ozório (CANGO) e do Território Federal do Iguaçu (TFI) em 1943; b) A ação da Clevelândia Industrial Territorial Ltda. (CITLA) e outras companhias colonizadoras; c) A criação do Grupo Executivo para as Terras do Sudoeste do Paraná (GETSOP), que atuou na região entre 1962 e 1974 transformou mais de 50.000 posseiros em proprietários de terras $(2003$, p. 148).

Vejamos sinteticamente como se deram essas fases de ocupação da região.

\section{A CRIAÇÃO DA CANGO E DO TFI E SUA INFLUÊNCIA NO POVOAMENTO DO SUDOESTE E OESTE DO PARANÁ}

O processo de transformação da sociedade brasileira, do qual fez parte a colonização do Sudoeste e Oeste do Paraná, teve "profundas ligações com o momento histórico da Revolução de 1930, com a implantação de um Estado criador das classes sociais modernas, da industrialização e das relações cidadecampo" (EMER, 1991, p. 83-84). Os ideais varguistas, de base nacionalista, 
buscaram ocupar os "espaços vazios" pela redistribuição da população, formulando a política da "Marcha para Oeste", que visava interligar os núcleos desenvolvidos, com regiões pouco ocupadas pelo capital, tiveram impactos significativos na história do Sudoeste e Oeste do Paraná, em meados do século $X X$.

O espírito nacionalista, centralizador e ditatorial de Vargas, levou-o a dar um golpe de estado e instituir o chamado Estado Novo (1937-1945). Foi nesse período que diversas ações foram executadas para nacionalizar e ocupar os espaços de fronteira do Brasil. Segundo Emer, a "Marcha para Oeste" continha os aspectos conjunturais do Estado Novo. As fronteiras deveriam ser ocupadas "por nacionais e não por estrangeiros com possíveis ideologias exóticas" como ocorreu nos movimentos operários dos centros urbanos" (1991, p. 133). Foi nesse contexto que em 1938, o governo anunciou à nação, a política da "Marcha para o Oeste". Tal ação visava estimular novas fronteiras agrícolas, visto que a agricultura ainda era a principal base da economia nacional. Como afirmou Emer, foi "um movimento liderado por chefes carismáticos, comandantes autocráticos, mas protetores" (EMER, 1991, p. 132).

Nesse sentido foram tomadas várias ações que tiveram impactos diretos nas regiões Oeste e Sudoeste do Paraná. Segundo Emer, em 1941, o Governo Federal incluiu a construção da BR-35 (atual BR 277) no Programa Rodoviário da "Marcha para Oeste", trazendo significativas melhorias e criando as possibilidades de integração da região Oeste à economia nacional. "A partir da construção da BR-35, estavam criadas as condições de direcionamento para a região de investimentos capitalistas, ampliação de seu modo de produção e de suas relações sociais" (EMER, 1991, p. 134).

Foi nesse mesmo período que se deu a criação da CANGO no Sudoeste do Paraná. Pelo Decreto n. 12.417, de 12 de maio de 1943, o Presidente Getúlio Vargas determinou o seguinte:

Art. 10 Fica criada a Colônia Agrícola Nacional "General Osorio", no Estado do Paraná, na faixa de 60 quilômetros da fronteira, na região Barracão - Santo Antônio, em terras a serem demarcadas pela Divisão de Terras e Colonização, do Departamento Nacional da Produção Vegetal, do Ministério da Agricultura. Parágrafo único. A área a ser demarcada não será inferior a 300.000 hectares (BRASIL. Decreto, 12.417, de 1943).

Não há dúvidas de que a criação da CANGO fez parte da política de interiorização denominada de "Marcha para Oeste", pois, o Decreto 12.417 se reportou ao Decreto n. 3.059, de 1941, que respaldou a "criação de Colônias 
Agrícolas Nacionais", em todo o território. É nessa mesma lógica que devemos entender a criação de cinco territórios federais, em áreas de fronteiras, alguns meses depois, pelo Decreto-Lei n. 5812, de 13 de setembro de 1943. Dentre eles estava o Território Federal do Iguaçu, que cobria parte expressiva da fronteira brasileira com a Argentina e o Paraguai.

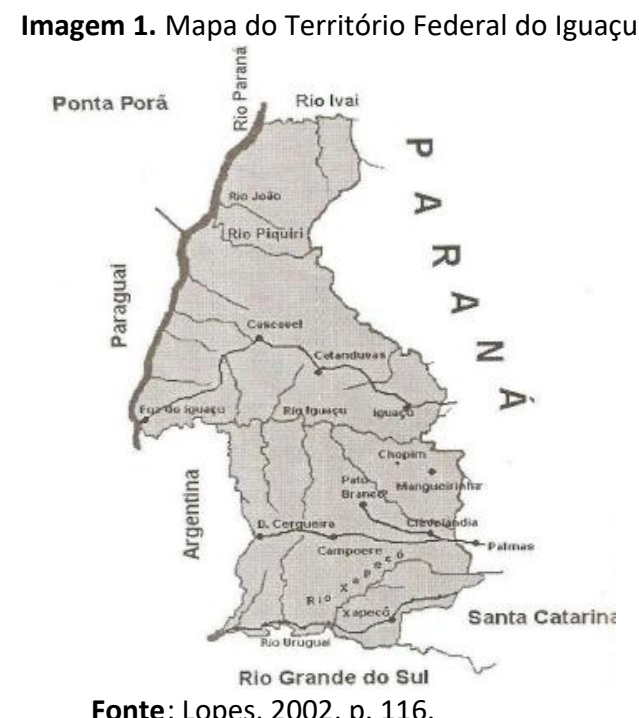

Fonte: Lopes, 2002, p. 116.

Um dos principais objetivos do Governo Federal com a criação da CANGO e do TFI foi atrair o excedente de mão-de-obra agrícola do Rio Grande do Sul e Santa Catarina para o Sudoeste e Oeste do Paraná, visto que lá já havia escassez de terras para o trabalho na agricultura.

Segundo Gregory (2002), a migração sulista para as regiões Sudoeste e Oeste do Paraná foi devido ao excedente populacional nas colônias de imigrantes do sul; pelo esgotamento das possibilidades de expansão das fronteiras agrícolas; pela redução da fertilidade do solo causada pela forma de cultivo.

Os agricultores recebiam ou compravam pequenos lotes de terras, da CANGO ou de companhias colonizadoras privadas, para se fixarem na região. Coube a CANGO ou as companhias colonizadoras criar infraestrutura mínima nos núcleos coloniais, construindo estradas, casas, igrejas, comércio e escolas. Conforme indicou Gregory (2002), nestes locais os agricultores se instalavam e reproduziam as técnicas e costumes agrícolas das modalidades de "colônias" existentes em seus locais de origem. $\mathrm{O}$ objetivo das novas áreas era desafogar o excedente populacional nas regiões de origem dos colonos e garantir a produção de excedentes agrícolas para consumo e comercialização, em troca 
do pagamento pela terra. Para os colonos, a terra era o componente fundamental de subsistência.

Com a criação da CANGO e do $\mathrm{TFI}^{2}$ na primeira metade da década de 1940, o governo Vargas estimulou e deu garantias as famílias do sul que almejavam a posse de um pedaço de terra para plantar nas regiões Sudoeste e Oeste do Paraná. No caso da CANGO, conforme indicou Wachowicz, havia características de Reforma Agrária, pois foram criadas as condições mínimas necessárias para estimular a fixação dos migrantes à nova terra, entre elas:

[...] a - as terras seriam distribuídas gratuitamente; $b$ - a madeira seria dada para a construção de sua casa; c - as ferramentas agrícolas e sementes seriam fornecidas pela colônia; $d$ - Os exames médicos e odontológicos seriam gratuitos na chegada; e- a produção seria levada aos centros de comercialização por caminhões da própria colônia (WACHOWICZ, 2002, p. 219-20).

As condições oferecidas pela CANGO foram muito atrativas e, por isso, segundo Wachowicz, "a população colonial como que explodiu. De 467 famílias em 1947, subiu para 2725 em 1956" (2002, p. 220).

Não há dúvidas de que as iniciativas do Governo Federal, conhecidas como "Marcha para o Oeste", foram fundamentais para a colonização das regiões Sudoeste e Oeste do Paraná, seja distribuindo terras gratuitamente ou autorizando a venda de terras pelas companhias colonizadoras. A história mostrou que a relação entre as companhias colonizadoras e os colonos não foi harmônica, como veremos a seguir.

\section{A CITLA E OS ARRANJOS POLÍTICOS PARA EXPLORAR OS COLONOS/POSSEIROS}

A CANGO entregava aos colonos que chegavam à colônia uma permissão por escrito para ocupar as terras, dando a eles o direito de posse, mas não o registro da propriedade. Aconteceu que durante a viagem ou enquanto as habitações não tinham condições dignas de abrigo, muitos desses documentos foram extraviados/destruídos. Segundo Lazier, para agravar mais a situação, a Clevelândia Industrial Territorial Ltda. (CITLA), entrou na região em 1950 alegando ser "proprietária de cerca de 500.000 hectares de terra, apresentando título fornecido pelo governo Federal. Este título conseguido de forma ilegal e imoral". (2003, p. 150).

\footnotetext{
${ }^{2}$ O Território Federal do Iguaçu foi extinto com a aprovação da Constituição em setembro de 1946.
} 
A CITLA efetuou uma negociação, pela qual um herdeiro de indenizações (José Rupp, cujo processo judicial teve origem no início do século $X X$, na disputa pela exploração de áreas de terra envolvendo os interesses de Rupp e da Companhia de Estradas de Ferro São Paulo-Rio Grande), que há muito tempo esperava ganhar a causa sobre a posse das terras da região, cedeu seu crédito à CITLA, numa negociação acertada em julho de 1950. A partir daquela data, o Estado ficou "devendo" à CITLA. Segundo Lazier, "a partir daí aconteceu o 'milagre', conforme documentação existente: aquilo que era ilegal passou a ser legal; aquilo que era indevido passou a ser legítimo; aquilo que era indeferido passou a ser deferido" (1997, p. 48). A CITLA contou a seu favor, além da negociata dos direitos de Rupp, com as ligações políticas e partidárias com políticos representantes do Estado do Paraná e da União. Assim as tramitações na justiça foram facilitadas, tanto que todas as portas se abriram e, em 17 de novembro de 1950, quando Moises Lupion governava o Paraná e Eurico Gaspar Dutra, era Presidente da República foi fechado o acerto indenizatório entre a CITLA e a Superintendência das Empresas Incorporadas do Patrimônio Nacional, "a titulação para a CITLA da gleba Missões e parte da gleba Chopim como pagamento daquele débito" (1997, p. 48). Conforme indicou Lazier, o Governador do Paraná Moisés Lupion era um dos sócios da CITLA e o partido político que governava o Paraná era o mesmo que governava o Brasil, o PSD. Esse escândalo foi chamado de "A maior bandalheira da República" (1997, p. 49).

Segundo Wachowicz, em 1950, sob o governo de Moisés Lupion, a CITLA tentou legalizar a compra irregular das terras nos cartórios da região, mas diante do não reconhecimento da posse pelos cartorários, a solução encontrada pelo governador foi criar "um cartório em Santo Antônio do Sudoeste e a mesma foi imediatamente registrada" (2002, p. 221). Após o registro da escritura, ainda em 1950, a Companhia instalou escritórios em Francisco Beltrão e Santo Antônio do Sudoeste.

Com todo esse respaldo político, a CITLA interferiu diretamente na vida dos agricultores que se instalaram na região causando muitos males, como veremos mais adiante, pois eles não possuíam documentos de proprietários definitivos.

Todavia, a farsa da documentação das terras em nome da CITLA começou a ser desmascarada, pois, em 1950 houve eleições para governador do Estado e o vencedor foi o candidato da oposição, Bento Munhoz da Rocha Neto. Segundo Wachowicz, Rocha Neto "proibiu às coletorias estaduais da região o fornecimento da Sisa (imposto estadual recolhido na ocasião da escrituração de um imóvel) para impedir que a CITLA pudesse passar escritura aos que comprassem suas terras" (2002, p. 221). 
Conforme indicou Lazier, no início de 1951, ao encaminhar a documentação ao tribunal de contas da União para sacramentar a negociação, os desembargadores perceberam as falhas no processo e encaminharam-no para o Congresso Nacional com a seguinte argumentação:

\begin{abstract}
Esse Tribunal, tendo presente o processo encaminhado pelo Ofício $\mathrm{n}-2$ de 3 de janeiro do ano em curso, da Superintendência da Empresa Incorporada ao Patrimônio Nacional, relativa à escritura pública de doação e pagamento celebrada em 17/11/1950 entre a superintendência citada e a Sociedade Clevelândia Industrial Territorial Ltda. (CITLA) resolveu, em 9 de janeiro do corrente ano, recusar o registro de escritura, preliminarmente, por que não houve prévia autorização do Senado Federal como determina o parágrafo 2, artigo 156 da Constituição Federal (LAZIER, 1997, p. 50).
\end{abstract}

A decisão do tribunal de Contas de encaminhar ao Congresso Nacional escancarou a farsa da posse da terra pela CITLA. Como já indicado, Rocha Neto criou alguns entraves para a atuação da CITLA na região porque havia uma disputa na justiça, pela qual a União pedia o cancelamento da escritura da CITLA. O Instituto Nacional de Imigração e Colonização (INIC) reivindicava na justiça os direitos da CANGO, além disso, a outra concorrente da CITLA, a PINHO E TERRAS esperava por seus direitos sobre parte da mesma gleba (LAZIER, 1997).

Em 1951, Getúlio Vargas voltou a poder eleito pelo voto popular, com isso a política nacional de interiorização foi retomada, fortalecendo as ações do Estado frente as companhias colonizadoras. Dificultadas as ações da CITLA, por todo o período de (1951-1955), abriu caminhos para que os colonos do Rio Grande do Sul e Santa Catarina, migrassem para a região Sudoeste e Oeste do Paraná em grande quantidade. De acordo com Wachowicz, "Cada dia entravam de 10 a 20 famílias só em Francisco Beltrão. 0 rápido crescimento populacional fez aumentarem os problemas políticos já existentes" (2002, p. 221).

Em 1951 foram criados os municípios de Barracão, Capanema, Francisco Beltrão, Pato Branco e Santo Antonio do Sudoeste, mas a emancipação se deu em 1952, com a posse dos prefeitos eleitos. O processo eleitoral em todo o Sudoeste, foi bem tenso devido as disputas políticas, envolvendo os correligionários de Lupion e os adeptos do Governador Munhoz da Rocha Neto.

Em 1955 elegeu-se Presidente da República, Jucselino Kubitchek, com o slogam de campanha "50 anos em 5", e junto com ele, como companheiro de partido, voltou ao cargo de governador do Paraná, Moisés Lupion, com uma 
esmagadora vitória, levando seu partido a conquistar todas as Prefeituras do Sudoeste. De posse do cargo liberou as escrituras para a CITLA, mas segundo Wachowicz, exigiu duas imobiliárias formadas por elementos do chamado Grupo Lupion: "a Companhia Comercial e Agrícola Paraná Ltda. (Comercial); a Companhia Colonizadora Apucarana Ltda. (Apucarana)". À Comercial coube a região do Verê e à Apucarana a região da fronteira com a Argentina (2002, p. 222). Pelo empenho das companhias em cobrar as terras dos colonos, imaginava-se que dentro dos três anos que restavam do mandato de Lupion, tudo seria resolvido da melhor forma possível, do ponto de vista das Companhias e do próprio governo.

\section{A REVOLTA DOS POSSEIROS DO SUDOESTE DO PARANÁ EM 1957}

Os trabalhos de aberturas das estradas foram iniciados pela CITLA, fazendo as ligações entre Pato Branco, Francisco Beltrão e Barracão, Capanema. Os caminhos abertos serviram ao mesmo tempo como acesso para a Companhia explorar a região, mas também facilitou a entrada de migrantes sulistas para ocupar o Sudoeste e o Oeste do Paraná. Na época muitas famílias entravam diariamente, preocupando ainda mais as companhias que controlavam a venda de terras. As rádios de Francisco Beltrão e Pato Branco convidavam diariamente os colonos para que viessem nos escritórios das companhias a fim de regularizar suas terras.

No atendimento aos colonos, os funcionários das companhias exigiam assinaturas em promissórias, para regularizar suas dívidas, assim muitos posseiros desinformados assinavam as promissórias mesmo sem entender bem o que poderia acontecer. Os políticos da oposição tentavam de várias formas alertar os colonos para que não assinassem documento nenhum. Sobre isso Wachowicz relatou:

Os colonos que se negavam a assinar os papéis passavam a ser ameaçados de morte. Tratores passavam por cima de suas casas, com a alegação de que ali passaria uma estrada. As Companhias contrataram jagunços e pistoleiros; muitos eram tirados das penitenciárias do Estado ou recrutados no Norte do Paraná. Os apelos dos colonos às autoridades estaduais e federais não encontravam acolhida. Os capangas das companhias passaram a andar ostensivamente armados (2002, p. 223).

Em abril de 1957, teve início o processo do levante dos posseiros do Sudoeste do Paraná. Conforme as companhias contratavam jagunços, os colonos também se armavam e contratavam pistoleiros, quando podiam. Os primeiros confrontos armados entre posseiros e jagunços ocorreram na 
fronteira com a Argentina. Com a deflagração dos conflitos, muitos colonos retornaram aos lugares de origem no sul do país, alguns se refugiaram na Argentina, outros migraram para o Oeste do Paraná, mas muitos ficaram e enfrentaram a luta até o fim.

Segundo Wachowicz, as delegacias de polícia sofreram influências das companhias e a desconfiança dos colonos, pois os inquéritos só eram abertos quando eram contra os colonos e os demais eram acobertados. As estradas foram bloqueadas e só entravam colonos que assinassem os papéis de compromisso com as companhias. Revoltados os colonos tomaram as sedes de Capanema e Pérola do Oeste. Enquanto isso, a Companhia Apucarana, centrava suas forças no domínio da região de Santo Antônio do Sudoeste, as duas frentes se posicionavam num clima de guerra pela posse das terras. Os políticos da oposição procuraram tirar proveito da situação e pediam intervenção federal, e apoiavam manifestações contra o governador do Estado Moisés Lupion (2002, p. 223-24).

O governo Lupion, que se encontrava numa situação complicada, optou por uma alternativa de conciliação.

Foi então enviado para a região em conflito um experimentado policial, o coronel Alcebíades Rodrigues da Costa. Este chegou a Capanema, via Foz do Iguaçu. O coronel Alcebíades encontrou na região mais de dois mil colonos com armas na mão. Para desestruturar os colonos, o coronel organizou uma espécie de "polícia civil". Seus membros eram os de maior liderança e com isso foram colocados a serviço da polícia. Para Santo Antônio foi enviado o coronel José Henrique Dias, que com muita dificuldade conseguiu retirar os homens armados da companhia Apucarana. Desta forma foi impedido o conflito direto entre as partes (WACHOWICZ, 2002, p.224-25).

Enquanto o conflito na fronteira era incendiado e controlado, na região de Francisco Beltrão, Verê, Dois Vizinhos, Jaracatiá, Costa do Iguaçu e outros, a Companhia Comercial estava no comando, pois o governo tinha substituído os delegados e inspetores de quarteirão, por funcionários simpáticos da mesma. Tudo o que acontecia era acobertado em favor da companhia que controlava a entrada e saída dos colonos na região. A violência e crimes cometidos por parte das companhias ficavam sem punições conforme cita Wachowicz:

O acontecimento que estarreceu a região foi a chacina da família do farrapo João Saldanha, com requintes de crueldade. Os ânimos se exaltaram. O governo do Paraná tentou tirar a Comercial da região, como fez com a Apucarana na região da fronteira. Esta se negou a sair. 
Seus diretores alegaram que já haviam feito muito investimento e não podiam mais recuar (2002, p. 226. Grifo no original).

Segundo o mesmo autor, os políticos oposicionistas se articularam para planejar estratégias, entre elas, estava a de dominar as cidades envolvidas e entregar ao governo federal. Os líderes que se destacaram nesse planejamento estratégico foram o senador Othon Mäeder e o advogado de Pato Branco, Edu Potiguara Bublitz (2002, p. 226).

Para organizar o levante, a região foi dividida em três partes: Pato Branco, Francisco Beltrão e Santo Antônio do Sudoeste. As emissoras de rádio foram elementos-chave, que muito contribuíram para a comunicação entre os colonos. Pato Branco e Francisco Beltrão, cidades que possuíam esses recursos foram escolhidas para centralizar e dirigir o movimento. Uma junta governativa comandou o levante em Pato Branco, o Líder Walter Pecoits e mais um destacamento do exército assegurou o comando do levante em favor dos colonos em Francisco Beltrão.

O levante branco, assim definido por Wachowicz, iniciou no dia 9 de outubro de 1957, em Pato Branco e no dia seguinte em Francisco Beltrão e em Santo Antônio, onde atraiu até o Cônsul brasileiro de Posadas na Argentina, assim a fronteira estava correndo risco de se tornar num Conflito Internacional. As repercussões do levante sensibilizaram a esfera federal, através do Ministro da Guerra, que após ler o relatório do Cônsul, imediatamente deu o ultimatum ao governador Lupion, para que retirasse as companhias da região para evitar uma intervenção federal. A preocupação do Governo Federal era de que em 1960 aconteceriam as eleições e esses conflitos que tinham se arrastado demais, prejudicavam o prestígio político do governo do Paraná, que se refletia a nível nacional por ser do mesmo partido político do Presidente da República Juscelino Kubitchek. Por essas razões, o Governo do Paraná envolvido no conflito do lado das companhias, foi forçado a abandonar suas pretensões particulares em favor de vantagens políticas a nível federal (2002, p. 226-27. Grifos no original). 
Imagem 2 - Posseiros destroem os papéis da CITLA em 10 de outubro de 1957

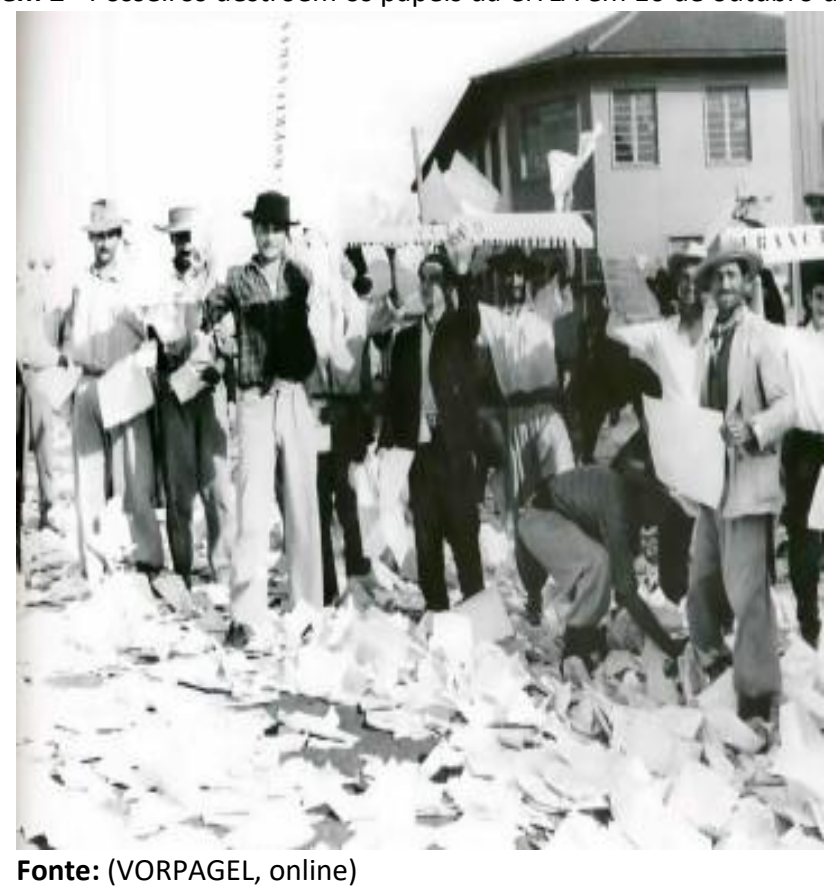

No Oeste do Paraná, os embates entre colonos/posseiros e as companhias não chegaram ao extremo, como no Sudoeste, mas, segundo Emer também "ocorreram conflitos e violências entre compradores de terras, madeireiras, especuladores e jagunços contratados pelas partes interessadas" (1991, p. 145).

A organização e ação do povo frente aos conflitos gerados pela posse da terra evidencia a força popular, quando está coesa frente uma causa.

\section{O GETSOP E A REGULARIZAÇÃO DA POSSE DA TERRA: DE POSSEIROS A PROPRIETÁRIOS}

Após a expulsão da CITLA em 1957, a legalização das terras era o principal objetivo da maioria dos posseiros e políticos do Sudoeste do Paraná. O sonho de transformar as posses em propriedades definitivas motivou a formação de uma Comissão com a finalidade de visitar a capital federal para conversar com os candidatos a Presidente da República, que disputavam o pleito em 1960. O interesse dessa comissão era firmar um compromisso de voto com o candidato que assumisse a causa da regularização das terras dos posseiros do Sudoeste do Paraná. A primeira tentativa foi com o candidato 
Teixeira Lott, que não mostrou interesse pela causa. A comissão conversou então com Jânio Quadros, o qual assumiu o compromisso, de que se eleito fosse, solucionaria o problema, desapropriando a área e titulando a terra para os posseiros.

Em razão desse compromisso, a sua votação foi muito expressiva no Sudoeste. Ao ser eleito Presidente da República, cumpriu sua promessa ao baixar o decreto № 50.379, de 27 de março de 1961, pelo qual declarou de utilidade pública, sujeitas a desapropriação, as terras da gleba Missões e parte da gleba Chopin, localizadas no Sudoeste do Paraná. E pelo Decreto no 50.494, de 25 de abril determinou o regime de urgência para a desapropriação das terras.

Em 25 de agosto de 1961, Jânio Quadros renunciou ao cargo de presidente. Em seu lugar assumiu o vice, João Goulart, que manteve o compromisso de Jânio Quadros, pois, em 19 de março de 1962, assinou o Decreto no 51.431, que criou o Grupo Executivo para as Terras do Sudoeste do Paraná (GETSOP), o qual assumiu a tarefa de regularizar as terras, transformando os posseiros em proprietários. O GETSOP atuou entre 1962 e 1974 e, segundo Lazier, durante esse período "expediu 43.383 títulos de propriedade, referente a 56.936 lotes, assim divididas: 12.413 nas áreas urbanas e 30.970 nas zonas rurais" (2003, p 148).

Além de regularizar as terras, o órgão prestou serviços com máquinas às prefeituras abrindo estradas, estimulou a formação de cooperativas de agricultores etc. Conforme indicou Lazier: "No setor educacional foi significativa a participação do GETSOP. Construiu 221 escolas, sendo 51 unidades de alvenaria e 170 de madeira". 0 autor salientou que o impulso do GETSOP, no desenvolvimento e produtividade da região repercutiu como uma "verdadeira reforma agrária no Sudoeste do Paraná". A situação dos migrantes teria sido mais difícil, se durante esse período não pudessem contar com a contribuição desse órgão. Esse trabalho foi realizado com um quadro efetivo de no "máximo 181 pessoas", transformando "cerca de 50.000 posseiros em proprietários" (LAZIER, 2003, p. 153).

\section{CONSIDERAÇÕES FINAIS}

Como vimos, desde o começo da República, o território que abriga as regiões Sudoeste e Oeste do Paraná foi palco de intensas lutas pelo controle da posse da terra. A criação da CANGO e do TFI, uma ação articulada ao movimento maior de interiorização do Brasil, conhecido como "Marcha para Oeste", possibilitou a afetiva ocupação territorial da região, majoritariamente feita por agricultores vindos do Rio Grande do Sul e Santa Catarina. A CANGO 
viabilizou as condições mínimas para a sobrevivência dos colonos nos primeiros anos de vida na região, todavia, o interesse de grupos colonizadores, articulados ao poder de alguns políticos e com a utilização de práticas criminosas, como a falsificação de títulos de terras, passaram a reivindicar a posse das terras, com o intuito de comercializá-las.

A ação das companhias colonizadoras, por um lado obrigou muitos posseiros a voltarem para o Sul, ou a pagarem pela terra, por outro, estimulou a organização e a mobilização dos agricultares, para juntos lutarem pela posse da terra.

A união dos posseiros para defender seus direitos foi uma ação que deixou um significativo legado para a população que habita o Sudoeste e o Oeste do Paraná, que, atualmente figuram como principais berços do cooperativismo e de outras práticas associativas, sendo essenciais para garantir o desenvolvimento econômico, social e educacional da região que abriga a Unioeste.

A partir do exposto, concluímos que é de fundamental importância o conhecimento da história regional, pois, a partir dele ganhamos força política, identidade social e cultural e compreendemos melhor a dinâmica das transformações no âmbito regional e nacional.

\section{REFERÊNCIAS}

BRASIL. Decreto - Lei № 3.059 de 14 de fevereiro de 1941. Dispõe sobre a criação de Colônias Agrícolas Nacionais. Disponível em: http://www2.camara.leg.br/legin/fed/declei/1940-1949/decreto-lei-3059-14fevereiro-1941-413001-publicacaooriginal-1-pe.html Acesso em 15 abr. 2020.

BRASIL. Lei no. 12.417 de 12 de maio de 1943. Cria a Colônia Agrícola Nacional General Osório, no Estado do Paraná. Disponível em: http://www2.camara.leg.br/legin/fed/decret/1940-1949/decreto-12417-12maio-1943-450906-publicacaooriginal-1-pe.html Acesso em: 15 abr. 2020.

BRASIL. Decreto-lei no 5.812, de 13 de setembro de 1943. Cria os Territórios Federais do Amapá, do Rio Branco, do Guaporé, de Ponta Porã e do Iguaçu. Disponível em: <http://www.jusbrasil.com.br/legislacao/126642/decreto-lei5812-43> Acesso em: 15 abr. 2020. 
BRASIL. Decreto-Lei no 5.839, de 21 de setembro de 1943. Dispõe sobre a administração dos Territórios Federais do Amapá, do Rio Branco, do Guaporé, de Ponta Porã e do Iguaçu. Disponível em:

http://www2.camara.leg.br/legin/fed/declei/1940-1949/decreto-lei-5839-21setembro-1943-415958-norma-pe.html Acesso em: 15 abr. 2020.

BRASIL. Decreto no 50.379, de 27 de março de 1961. Declara de utilidade pública para fins de desapropriação a gleba "Missões" e parte da gleba "Chopim" situadas na faixa da fronteira, no Estado do Paraná. Disponível em: http://www2.camara.leg.br/legin/fed/decret/1960-1969/decreto-50379-27marco-1961-389943-publicacaooriginal-1-pe.html Acesso em: 15 abr. 2020.

BRASIL. Decreto no 50.494, de 25 de abril de 1961. Determina regime de urgência para a desapropriação por utilidade pública, decorrente do Decreto $\mathrm{n}^{\circ}$ 50.379, de 27 de março de 1961, e dá outras providências. Disponível em: <http://www2.camara.leg.br/legin/fed/decret/1960-1969/decreto-50494-25abril-1961-390330-publicacaooriginal-1-pe.html> Acesso em: 15 abr. 2020.

BRASIL. Decreto no 51.431, de 19 de março de 1962. Cria o Grupo Executivo para as Terras do Sudoeste do Paraná. Disponível em:

<http://www2.camara.leg.br/busca/?

$\mathrm{o}=$ relevance $\& \mathrm{v}=$ legislacao \&camaranet $=\&$ colecao=S\&conteudolegin=\&numero $=51431+\&$ ano=1962> Acesso em: 15 abr. 2020.

EMER, I. O. Desenvolvimento histórico do Oeste do Paraná e a construção da escola. Rio de Janeiro - RJ, FGV, 1991.

GREGORY, V. Os eurobrasileiros e o espaço colonial: migrações no Oeste do Paraná. Cascavel - PR: EDUNIOESTE, 2002.

LAZIER, H. Análise Histórica da Posse de Terra no Sudoeste Paranaense. 2. ed. Francisco Beltrão-PR: GRAFIT, 1997.

LAZIER, H. Paraná: Terra de todas as gentes e de muita história. Francisco Beltrão, PR: GRAFIT, 2003.

LOPES, S. O Território do Iguaçu no contexto da "Marcha para Oeste". Cascavel, PR: Edunioeste, 2002.

PADIS, P. C. Formação de uma economia Periférica: o caso do Paraná. São Paulo: HUCITEC; Curitiba: Sec. da Cultura e do Esporte do Governo do Estado do Paraná, 1981.

SBARDELOTTO, D. K.; CASTANHA, A. P. A pesquisa em História da Educação no sudoeste do Paraná: análise e perspectiva. Revista de História e Historiografia da Educação, v.2, p.189 - 213, 2018. 
VORPAGEL, E. K. A revolta dos posseiros no Sudoeste do Paraná em 1957. Disponível em:

http://www.diaadiaeducacao.pr.gov.br/portals/pde/arquivos/300-2.pdf Acesso em: 05 mar. 2020.

WACHOWICZ, R. C. História do Paraná. 10. ed. Curitiba: Imprensa Oficial do Paraná, 2002. 